${ }^{1}$ Государственный научный центр Российской Федерации Федеральный медицинский биобизический иентр им. А.И. Бурназяна, Москва

${ }^{2}$ Краевая клиническая больница, Барнаул

${ }^{3}$ Алтайский государственный медииинский университет, Барнаул

${ }^{4}$ Самарская областная клиническая больница им. В.Д. Середавина

\title{
Особенности показателей
} эякулята и способы коррекции нарушений сперматогенеза у мужчин различных возрастных групп

\author{
Р.Т. Алиев, д.м.н., проф., ${ }^{1,2}$ Р.Р. Алиев ${ }^{3}$, С.М. Пикалов ${ }^{4}$
}

Адрес для переписки: Роман Тофикович Алиев, romanaliev@yandex.ru

Для цитирования: Алиев Р.Т., Алиев Р.P., Пикалов С.M. Особенности показателей эякулята и способы коррекции нарушений сперматогенеза у мужчин различных возрастных групп // Эффективная фармакотерапия. 2019. Т. 15. № 16. С. $26-33$.

DOI 10.33978/2307-3586-2019-15-16-26-33

Представлены результаты изучения проблемы вторичного бесплодия умужчин. На первом этапе было установлено, что умужчин старией возрастной группы (старше 40 лет) меньше объем эякулята, ниже уровень прогрессивно подвинных и морбологически нормальных сперматозоидов. Кроме того, у них ослаблена антиоксидантная защита эякулята, снижена функция тестикул и повышен уровень фрагментации ДНК сперматозоидов. На втором этапе пациенты 40 лет и старше принимали комплекс БЕСТФертил ${ }^{\circ}$ чтоо способствовало статистически значимому $(p<0,05)$ улучшению основных параметров эякулята, усилению антиоксидантной защитты и снижению уровня фрагментации ДНК сперматозоидов.

Ключевые слова: сперматогенез, эякулят, мужское бесплодие жению активности сперматогенной функции [3]. В 30-75\% случаев причины мужского бесплодия остаются невыясненными (идиопатическое бесплодие) [4-6]. Но даже установление вероятных этиологических факторов (варикоцеле, инфекционно-воспалительные процессы, токсические вещества и др.) не позволяет с точностью утверждать, что именно они привели к бесплодию.

В последние годы активно изучается влияние на мужскую фертильность гиперпродукции активных форм кислорода: озона, свободных радикалов, перекиси водорода [7-9]. В небольших количествах активные формы кислорода необходимы для нормальной регуляции функции сперматозоидов, их гиперактивации и акросомальной реакции $[10,11]$. Но избыточная продукция активных форм кислорода может стать причиной повреждения мембраны сперматозоидов, снижения их подвижности и нарушения оплодотворяющей способности [12-15]. Кроме того, активные формы кислорода непосредственно повреждают ДНК 
хромосом $[16,17]$ и инициируют апоптоз сперматозоидов [18], что в конечном счете приводит к бесплодию [19-21]. Однако остается неясным, насколько распространен окислительный стресс и насколько выражено повышение продукции активных форм кислорода при различных этиологически значимых состояниях, потенциально снижающих фертильность мужчин. Изучение воздействия свободных радикалов на генеративную функцию мужчин представляет значительный интерес.

Тестостерон играет одну из ключевых ролей в процессе сперматогенеза - сложного, продолжительного и упорядоченного процесса клеточного деления и дифференцировки под контролем эндокринных сигналов (гонадотропин-рилизинг-гормона, лютеинизирующего и фолликулостимулирующего гормонов, ингибина), паракринных сигналов, вырабатываемых в результате взаимодействия различных типов клеток семенных канальцев и интерстиция, а также аутокринных сигналов самоконтроля внутри клетки. В семенных канальцах тестостерон находится в концентрациях, которые в сотни раз превосходят его концентрацию в крови. Влияние старения на мужскую репродуктивную систему во многом зависит от индивидуальных особенностей мужчины, в том числе острых и хронических заболеваний, травм урогенитальной системы, а также образа жизни и факторов окружающей среды. Связанные со старением изменения репродуктивной системы охватывают все аспекты репродуктивной функции, включая нарушение регуляции гипоталамо-гипофизарно-гонадной системы и локальных аутопаракринных взаимодействий, влияние на тестикулярные стволовые клетки, нарушение строения яичек и сперматогенеза. В соответствии с несколькими теориями в центре клеточных событий, связанных со старением, находятся митохондрии. Особенно это касается процесса накопления окислительных повреждений клеток и тканей, в котором эти органеллы играют важную роль. Очевидно, что все вышеперечисленные процессы взаимосвязаны.

У молодых мужчин, не достигших возраста андропаузы [22] и не имеющих возрастного увеличения предстательной железы, причинами вторичного бесплодия могут быть низкое содержание или отсутствие сперматозоидов, нарушение морфологии или подвижности сперматозоидов. Таких пациентов традиционно обследуют для выявления варикоцеле, выясняют наличие в анамнезе соответствующих хирургических операций, системных заболеваний, психологических нарушений и вредных привычек, например курения и злоупотребления алкоголем. У пациентов старшего возраста тщательно исключают все вышеуказанные причины, а также проводят более широкое обследование для выявления заболеваний, связанных с мужским старением: синдрома возрастного андрогенного дефицита, синдрома мужской раздражительности, возрастного увеличения предстательной железы и применения связанных с этим лекарственных препаратов. Могут иметь значение нездоровый образ жизни, вредные привычки и хронические заболевания.

Видимо, старение активирует механизмы окислительного стресса [23] и увеличивает частоту окислительного повреждения нуклеиновых кислот в клетках [24]. Кроме того, к самым частым причинам мужского бесплодия относится нарушение нормального сперматогенеза и функции сперматозоидов [25]. Повышенные уровни активных форм кислорода обнаруживают у 30-80\% мужчин с бесплодием [26].

Мужчины старшего возраста с вторичным бесплодием требуют особого подхода. Старение само по себе существенно влияет на мужскую сексуальную функцию, параметры спермы и фертильность. Так, снижается оплодотворяющая способность, увеличиваются сроки наступления беременности,
Старение само по себе существенно

влияет на мужскую сексуальную функцию, параметры спермы и фертильность.

Так, снижается оплодотворяющая

способность, увеличиваются сроки

наступления беременности, повышаются

вероятность повреждения ДНК, частота

выкидышей и встречаемость пороков

развития плода

повышаются вероятность повреждения ДНК, частота выкидышей и встречаемость пороков развития плода. Сложность и недостаточная изученность физиологии стареющих мужчин наряду с влиянием хронических заболеваний, которые могут быть у пациента, делают решение проблемы весьма непростым. В этой связи актуально дальнейшее изучение проблемы репродуктивных нарушений у мужчин старшей возрастной группы.

\section{Материал и методы}

В исследование были включены 179 мужчин с доказанной фертильностью (не менее одного ребенка в браке).

Критерии включения:

- мужской пол;

- возраст 21-55 лет;

- наличие детей в браке;

- способность пациента понять суть исследования и дать письменное согласие на участие в клиническом исследовании.

Критерии исключения:

- азооспермия;

- инфекции репродуктивного тракта (Chlamydia trachomatis, Ureaplasma urealyticum, Mycoplasma hominis, Trichomonas vaginalis), диагностированные методом полимеразной цепной реакции;

- возраст моложе 21 года и старше 55 лет;

- лабораторные признаки бактериального простатита; 
- травмы половых органов в анамнезе;

- варикоцеле;

- соматическая патология в стадии декомпенсации;

- алкогольная или наркотическая зависимость;

- участие в другом клиническом исследовании в последние три месяца.

У пациентов, включенных в исследование, отслеживалось наличие сопутствующей патологии, оценивались основные параметры эякулята в соответствии с рекомендациями ВОЗ (2010), а также состояние системы перекисного окисления липидов эякулята, проводились дополнительные спермальные тесты (НВА-тест, исследование фрагментации ДНК сперматозоидов).

Результаты исследований обрабатывались общепринятыми методами. Рассчитывались следующие числовые характеристики клинико-лабораторных показателей:

- среднее и его стандартная ошибка (для количественных нормально распределенных признаков);

- медиана и интерквартильные интервалы (для количественных показателей с отличным от нормального видом распределения);

- относительные частоты (для качественных данных).

Таблица 1. Характеристика пациентов, принявиих участие в исследовании

\begin{tabular}{|l|l|l|}
$\begin{array}{l}\text { Возраст } \\
\text { пациентов }\end{array}$ & $\begin{array}{l}\text { Количество } \\
\text { человек, абс. }\end{array}$ & $\begin{array}{l}\text { Время, прошедшее с рождения } \\
\text { младшего ребенка в браке, лет }\end{array}$ \\
\hline $21-25$ & 17 & $2,1 \pm 1,18$ \\
\hline $26-30$ & 26 & $2,7 \pm 1,27$ \\
\hline $31-35$ & 31 & $4,3 \pm 2,13$ \\
\hline $36-40$ & 35 & $5,1 \pm 3,46$ \\
\hline $41-45$ & 33 & $6,2 \pm 4,05$ \\
\hline $46-50$ & 21 & $8,1 \pm 4,87$ \\
\hline $51-55$ & 16 & $10,3 \pm 5,36$ \\
\hline
\end{tabular}

Оценка значимости различий средних значений в независимых выборках определялась с использованием t-критерия Стьюдента (для количественных признаков при нормальном распределении данных и равенстве дисперсий), непараметрических критерия Манна - Уитни, двухвыборочного критерия Колмогорова - Смирнова (для количественных показателей при распределении, отличном от нормального, или различных дисперсиях), относительных частот по критерию хи-квадрат с поправкой Йетса (для качественных признаков). Разницу между средними значениями показателей считали значимой при $\mathrm{p}<0,05$.

Центральные тенденции и рассеяния количественных признаков, имеющих приближенно нормальное распределение, описывали средним значением (M) и средним квадратичным отклонением (s) в формате $\mathrm{M} \pm \mathrm{s}$. Центральные тенденции и дисперсии количественных признаков, не имеющих приближенно нормального распределения, описывали медианой и интерквартильным размахом (25-й и 75-й перцентили) [27].

Таблица 2. Частота сопутствующей патологии

\begin{tabular}{|l|l|l|l|l|l|l|}
\hline $\begin{array}{l}\text { Возраст } \\
\text { пациентов }\end{array}$ & $\begin{array}{l}\text { Артериальная } \\
\text { гипертензия }\end{array}$ & $\begin{array}{l}\text { Сахарный } \\
\text { диабет }\end{array}$ & $\begin{array}{l}\text { Хронический } \\
\text { простатит }\end{array}$ & $\begin{array}{l}\text { Доброкачественная гиперплазия } \\
\text { предстательнойелезы }\end{array}$ & Ожирение & Итого \\
\hline $21-25$ & 0 & 0 & 1 & 0 & 1 & 2 \\
\hline $26-30$ & 1 & 0 & 2 & 0 & 1 & 4 \\
\hline $31-35$ & 2 & 0 & 4 & 0 & 1 & 7 \\
\hline $36-40$ & 5 & 1 & 7 & 0 & 4 & 16 \\
\hline $41-45$ & 6 & 1 & 6 & 1 & 5 & 18 \\
\hline $46-50$ & 7 & 3 & 5 & 3 & 6 & 23 \\
\hline $51-55$ & 6 & 1 & 6 & 4 & 22 & 23 \\
\hline
\end{tabular}

Таблица 3. Основные параметры эякулята (по рекомендациям ВОЗ, 2010)

\begin{tabular}{|l|l|l|l|l|l|}
\hline $\begin{array}{l}\text { Возраст } \\
\text { пациентов }\end{array}$ & $\begin{array}{l}\text { Воздержание } \\
\text { перед сдачей } \\
\text { эякулята, дни }\end{array}$ & $\begin{array}{l}\text { Объем } \\
\text { эякулята, } \\
\text { мл }\end{array}$ & $\begin{array}{l}\text { Концентрация } \\
\text { сперматозоидов, } \\
\text { млн/мл }\end{array}$ & $\begin{array}{l}\text { Прогрессивно } \\
\text { подвижные } \\
\text { сперматозоиды, \% }\end{array}$ & $\begin{array}{l}\text { Морфологически } \\
\text { нормалыные } \\
\text { сперматозоиды, \% }\end{array}$ \\
\hline $21-25$ & $3,2 \pm 0,22$ & $4,2 \pm 0,22$ & $54,5 \pm 8,26$ & $45,0 \pm 5,27$ & $17,5 \pm 2,25$ \\
\hline $26-30$ & $3,3 \pm 0,25$ & $4,2 \pm 0,24$ & $57,3 \pm 9,32$ & $48,9 \pm 6,11$ & $18,8 \pm 2,35$ \\
\hline $31-35$ & $3,1 \pm 0,26$ & $4,3 \pm 0,22$ & $55,6 \pm 7,46$ & $47,4 \pm 5,39$ & $19,1 \pm 3,11$ \\
\hline $36-40$ & $3,7 \pm 0,18$ & $3,9 \pm 0,22$ & $52,1 \pm 10,23$ & $44,4 \pm 4,28$ & $18,2 \pm 3,23$ \\
\hline $46-50$ & $3,1 \pm 0,31$ & $3,5 \pm 0,18^{*}$ & $44,7 \pm 10,44^{*}$ & $44,2 \pm 5,73$ & $16,3 \pm 3,54$ \\
\hline $51-55$ & $3,8 \pm 0,24$ & $3,2 \pm 0,22^{*}$ & $37,9 \pm 10,23^{*}$ & $36,4 \pm 7,12^{*}$ & $13,2 \pm 2,99^{*}$ \\
\hline
\end{tabular}

* Разница по сравнению с показателями мужчин в возрасте $21-25$ лет статистически значима $(\mathrm{p}<0,05)$. 


\section{Первый этап}

Распределение пациентов по возрасту представлено в табл. 1. Анализ наличия сопутствующей патологии в различных возрастных группах выявил значительное увеличение встречаемости хронических заболеваний, способных влиять на фертильность, у пациентов старшего возраста (от 40 лет и старше) (табл. 2).

Состояние сперматогенеза оценивалось в соответствии с рекомендациями ВО3 (2010) (табл. 3). Оказалось, что с возрастом уменьшался объем эякулята, снижался уровень прогрессивно подвижных и морфологически нормальных сперматозоидов.

У пациентов старшей возрастной группы был повышен уровень малонового диальдегида и одновременно снижена активность антиоксидантных ферментов, что свидетельствовало об ослаблении антиоксидантной защиты эякулята (табл. 4). В свою очередь повышенный уровень свободных радикалов в эякуляте может приводить к повреждению сперматозоидов (повреждению мембран сперматозоидов, повышению уровня фрагментации ДНК сперматозоидов, гибели сперматозоидов) [13-15], что и было продемонстрировано в настоящем исследовании. Так, у пациентов с возрастом увеличивалось содержание сперматозоидов с фрагментированной ДНК и снижалась доля зрелых сперматозоидов, способных связываться с гиалуроновой кислотой.

При оценке уровня гормонов у пациентов старше 40 лет выявлено снижение уровня общего тестостерона с одновременным увеличением уровня фолликулостимулирующего и лютеинизирующего гормонов, а также глобулина, связывающего половые гормоны, что указывает на снижение функции тестикул. В ходе исследования значимых различий по уровню пролактина и тиреотропного гормона между группами не установлено (табл. 5).

\section{Второй этап}

Во второй части исследования была предпринята попытка улучшить сперматогенез у мужчин старшей

Таблица 4. Дополнительные параметры эякулята

\begin{tabular}{|l|l|l|l|l|l|}
\hline $\begin{array}{l}\text { Возраст } \\
\text { пациентов }\end{array}$ & $\begin{array}{l}\text { Малоновый } \\
\text { диальдегид, } \\
\text { мкмоль/л }\end{array}$ & ГП, ед/л & $\begin{array}{l}\text { СОД, } \\
\text { ед/л }\end{array}$ & $\begin{array}{l}\text { Уровень } \\
\text { фрагментации ДНК } \\
\text { сперматозоидов, \% }\end{array}$ & $\begin{array}{l}\text { НВА-тест, } \\
\%\end{array}$ \\
\hline $21-25$ & $2,1 \pm 0,2$ & $518,4 \pm 29,9$ & $326,0 \pm 29,3$ & $7 \pm 0,3$ & $91 \pm 2,3$ \\
\hline $26-30$ & $2,1 \pm 0,3$ & $524,3 \pm 23,0$ & $304,0 \pm 23,1$ & $7 \pm 0,6$ & $85 \pm 2,4$ \\
\hline $31-35$ & $2,3 \pm 0,2$ & $495,3 \pm 29,0$ & $285,0 \pm 18,5$ & $9 \pm 0,5$ & $79 \pm 2,2$ \\
\hline $36-40$ & $3,0 \pm 0,3$ & $456,8 \pm 19,0$ & $221,0 \pm 25,6^{*}$ & $12 \pm 0,7^{*}$ & $72 \pm 3,4^{*}$ \\
\hline $46-50$ & $3,2 \pm 0,4^{*}$ & $399,1 \pm 19,0^{*}$ & $192,5 \pm 25,1^{*}$ & $15 \pm 0,8^{*}$ & $65 \pm 2,3^{*}$ \\
\hline $51-55$ & $3,6 \pm 0,4^{*}$ & $320,5 \pm 17,0^{*}$ & $152,0 \pm 26,7^{*}$ & $18 \pm 0,9^{*}$ & $57 \pm 2,7^{*}$ \\
\hline
\end{tabular}

Примечание. ГП - глутатионпероксидаза; СОД - супероксиддисмутаза.

* Разница по сравнению с показателями мужчин в возрасте $21-25$ лет статистически значима $(\mathrm{p}<0,05)$.

\section{Таблица 5. Уровень гормонов, влияющих на сперматогенез}

\begin{tabular}{|l|l|l|l|l|l|l|}
\hline $\begin{array}{l}\text { Возраст } \\
\text { пациентов }\end{array}$ & $\begin{array}{l}\text { Общий } \\
\text { тестостерон, } \\
\text { нмоль/л }\end{array}$ & $\begin{array}{l}\text { ГСПГ, } \\
\text { нмоль/л }\end{array}$ & $\begin{array}{l}\text { ЛГ, } \\
\text { мМЕд/мл }\end{array}$ & $\begin{array}{l}\text { ФСГ, } \\
\text { мМЕд/мл }\end{array}$ & $\begin{array}{l}\text { Пролактин, } \\
\text { нг/мл }\end{array}$ & $\begin{array}{l}\text { ТТГ, } \\
\text { мкЕ/мл }\end{array}$ \\
\hline $21-25$ & $29,22 \pm 4,72$ & $17 \pm 3,75$ & $2,02 \pm 0,68$ & $2,04 \pm 1,38$ & $5,45 \pm 2,45$ & $1,24 \pm 0,08$ \\
\hline $26-30$ & $27,67 \pm 3,56$ & $16 \pm 2,77$ & $2,12 \pm 0,13$ & $3,14 \pm 1,45$ & $6,27 \pm 1,64$ & $1,32 \pm 0,09$ \\
\hline $31-35$ & $26,89 \pm 5,22$ & $18 \pm 4,25$ & $2,24 \pm 0,23$ & $3,55 \pm 1,37$ & $4,64 \pm 1,52$ & $1,35 \pm 0,06$ \\
\hline $36-40$ & $21,87 \pm 6,18$ & $20 \pm 3,64$ & $3,05 \pm 0,24$ & $6,04 \pm 1,65^{*}$ & $6,58 \pm 2,12$ & $1,75 \pm 0,06$ \\
\hline $41-45$ & $18,45 \pm 6,45^{*}$ & $26 \pm 4,55^{*}$ & $3,65 \pm 0,17$ & $9,25 \pm 2,12^{*}$ & $6,27 \pm 1,82$ & $2,02 \pm 0,10$ \\
\hline $46-50$ & $17,96 \pm 7,34^{*}$ & $32 \pm 3,25^{*}$ & $5,57 \pm 0,24^{*}$ & $11,10 \pm 1,88^{*}$ & $6,02 \pm 1,43$ & $1,92 \pm 0,12$ \\
\hline $51-55$ & $14,35 \pm 6,87^{*}$ & $45 \pm 5,65^{*}$ & $6,05 \pm 0,29^{*}$ & $13,25 \pm 3,25^{*}$ & $5,89 \pm 1,17$ & $1,82 \pm 0,14$ \\
\hline
\end{tabular}

Примечание. ГСПГ - глобулин, связывающий половые гормоны; ЛГ - лютеинизирующий гормон; ТТГ - тиреотропный гормон; ФСГ - фолликулостимулирующий гормон.

* Разница по сравнению с показателями мужчин в возрасте $21-25$ лет статистически значима $(\mathrm{p}<0,05)$.

возрастной группы. Согласно полученным результатам, снижение основных параметров эякулята и изменение гормонального фона наблюдались у пациентов старше 40 лет, поэтому в дальнейшем исследовании приняли участие мужчины этого возраста.

Для улучшения параметров эякулята пациенты принимали биологически активный комплекс БЕСТФертил ${ }^{\bullet}$ который представляет собой капсулы двух видов. Капсула «Утро» содержит $\mathrm{L}$-карнитин, L-аргинин, желатин (оболочка капсулы), коэнзим $\mathrm{Q}_{10}$, цинка лактат, фолиевую кислоту, селенометионин, аскорбиновую кислоту (витамин С), экстракт корня женьшеня, лактозу, кальция стеарат, диоксид титана, индигокармин (индиготин). В состав капсулы «Вечер» входят докозагексаеновая кислота, L-карнитин, желатин (оболочка капсулы), альфа-токоферола ацетат (витамин Е), глутатион, лактоза, каль- ция стеарат, диоксид титана, индигокармин (индиготин).

L-карнитин обеспечивает энергией зрелые сперматозоиды, улучшает их качество и подвижность, положительно влияет на морфологическое строение, концентрацию и подвижность сперматозоидов. При недостатке L-аргинина снижается количество сперматозоидов в семенной жидкости. Коэнзим $\mathrm{Q}_{10}$ принимает участие в окислительно-восстановительных реакциях, протекающих в половых клетках, улучшает морфологическое строение, оплодотворяющую способность сперматозоидов, повышает их подвижность. Цинк, будучи антиоксидантом, защищает половые клетки от повреждающего воздействия свободных радикалов. Кроме того, он входит в состав ферментов, участвующих в формировании и развитии сперматозоидов, и является компонентом 
Таблица 6. Уровень гормонов, влияющих на сперматогенез, у пациентов старших возрастных групп через шесть месяцев после лечения

\begin{tabular}{|c|c|c|c|c|c|c|c|c|c|c|c|c|}
\hline \multirow[t]{2}{*}{$\begin{array}{l}\text { Возраст } \\
\text { пациентов }\end{array}$} & \multicolumn{2}{|c|}{$\begin{array}{l}\text { Общий тестостерон, } \\
\text { нмоль/л }\end{array}$} & \multicolumn{2}{|l|}{\begin{tabular}{|l} 
ГСПГ, \\
нмоль/л \\
\end{tabular}} & \multicolumn{2}{|l|}{$\begin{array}{l}\text { ЛГ, } \\
\text { мМЕд/мI } \\
\end{array}$} & \multicolumn{2}{|c|}{ ФСГ, мМЕД/МЛ } & \multicolumn{2}{|c|}{ Пролактин, нг/мл } & \multicolumn{2}{|l|}{$\begin{array}{l}\text { TTГ, } \\
\text { мKE/мI } \\
\end{array}$} \\
\hline & \begin{tabular}{|l|} 
до \\
лечения
\end{tabular} & \begin{tabular}{|l} 
после \\
лечения
\end{tabular} & $\begin{array}{l}\text { до } \\
\text { лечения }\end{array}$ & \begin{tabular}{|l} 
после \\
лечения
\end{tabular} & $\begin{array}{l}\text { до } \\
\text { лечения }\end{array}$ & $\begin{array}{l}\text { после } \\
\text { лечения }\end{array}$ & $\begin{array}{l}\text { до } \\
\text { лечения }\end{array}$ & \begin{tabular}{|l} 
после \\
лечения
\end{tabular} & $\begin{array}{l}\text { до } \\
\text { лечения }\end{array}$ & \begin{tabular}{|l} 
после \\
лечения
\end{tabular} & \begin{tabular}{|l} 
до \\
лечения
\end{tabular} & $\begin{array}{l}\text { после } \\
\text { лечения }\end{array}$ \\
\hline $41-45$ & $18,45 \pm 6,45$ & $19,25 \pm 5,45$ & $26 \pm 4,55$ & $25,0 \pm 3,39$ & $3,65 \pm 0,17$ & $3,45 \pm 0,25$ & $9,25 \pm 2,12$ & $9,24 \pm 2,14$ & $6,27 \pm 1,82$ & $6,24 \pm 1,25$ & $2,02 \pm 0,10$ & $2,12 \pm 0,12$ \\
\hline $46-50$ & $17,96 \pm 7,34$ & $18,92 \pm 7,32$ & $32 \pm 3,25$ & $32,3 \pm 3,17$ & $5,57 \pm 0,24$ & $5,47 \pm 0,28$ & $11,10 \pm 1,88$ & $11,50 \pm 1,92$ & $6,02 \pm 1,43$ & $6,12 \pm 1,38$ & $1,92 \pm 0,12$ & $1,94 \pm 0,15$ \\
\hline $51-55$ & $14,35 \pm 6,87$ & $15,42 \pm 6,25$ & $45 \pm 5,65$ & $43,0 \pm 5,24$ & $6,05 \pm 0,29$ & $6,25 \pm 0,23$ & $13,25 \pm 3,25$ & $13,35 \pm 2,95$ & $5,89 \pm 1,17$ & $5,53 \pm 1,23$ & $1,82 \pm 0,14$ & $1,85 \pm 0,16$ \\
\hline
\end{tabular}

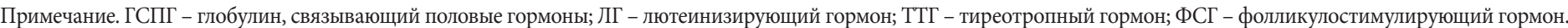

* Разница по сравнению с показателями до лечения статистически значима $(\mathrm{p}<0,05)$.

Таблица 7. Основные параметры эякулята у пациентов старших возрастных групп через иесть месяцев после лечения (по рекомендациям ВОЗ, 2010)

\begin{tabular}{|c|c|c|c|c|c|c|c|c|c|c|}
\hline \multirow[t]{2}{*}{$\begin{array}{l}\text { Возраст } \\
\text { пациентов }\end{array}$} & \multicolumn{2}{|c|}{$\begin{array}{l}\text { Воздержание перед } \\
\text { сдачей эякулята, дни }\end{array}$} & \multicolumn{2}{|c|}{ Объем эякулята, мл } & \multicolumn{2}{|c|}{$\begin{array}{l}\text { Концентрация } \\
\text { сперматозоидов, млн/мI }\end{array}$} & \multicolumn{2}{|c|}{$\begin{array}{l}\text { Прогрессивно } \\
\text { подвижные } \\
\text { сперматозоиды, \% } \\
\end{array}$} & \multicolumn{2}{|c|}{$\begin{array}{l}\text { Морфологически } \\
\text { нормальные } \\
\text { сперматозоиды, \% }\end{array}$} \\
\hline & $\begin{array}{l}\text { до } \\
\text { лечения }\end{array}$ & $\begin{array}{l}\text { после } \\
\text { лечения }\end{array}$ & $\begin{array}{l}\text { до } \\
\text { лечения }\end{array}$ & \begin{tabular}{|l} 
после \\
лечения
\end{tabular} & \begin{tabular}{|l|} 
до \\
лечения
\end{tabular} & $\begin{array}{l}\text { после } \\
\text { лечения }\end{array}$ & \begin{tabular}{|l} 
до \\
лечения
\end{tabular} & $\begin{array}{l}\text { после } \\
\text { лечения }\end{array}$ & $\begin{array}{l}\text { до } \\
\text { лечения }\end{array}$ & \begin{tabular}{|l|} 
после \\
лечения
\end{tabular} \\
\hline $41-45$ & $3,1 \pm 0,31$ & $3,2 \pm 0,24$ & $3,5 \pm 0,18$ & $3,6 \pm 0,14$ & $44,7 \pm 10,44$ & $56,8 \pm 9,47^{\star}$ & $44,2 \pm 5,73$ & $56,4 \pm 6,42^{\star}$ & $16,30 \pm 3,54$ & $24,4 \pm 2,94^{\star}$ \\
\hline $46-50$ & $3,8 \pm 0,24$ & $3,6 \pm 0,21$ & $3,2 \pm 0,22$ & $3,1 \pm 0,25$ & $37,9 \pm 10,23$ & $45,6 \pm 10,54^{\star}$ & $36,4 \pm 7,12$ & $43,6 \pm 6,22^{*}$ & $13,20 \pm 2,99$ & $21,2 \pm 2,45^{*}$ \\
\hline $51-55$ & $3,9 \pm 0,41$ & $3,4 \pm 0,32$ & $2,9 \pm 0,20$ & $3,0 \pm 0,21$ & $29,0 \pm 11,54$ & $41,0 \pm 12,24^{*}$ & $31,2 \pm 6,24$ & $39,4 \pm 5,84^{*}$ & $9,37 \pm 3,78^{*}$ & $15,6 \pm 2,84^{*}$ \\
\hline
\end{tabular}

* Разница по сравнению с показателями до лечения статистически значима $(\mathrm{p}<0,05)$.

секрета предстательной железы (улучшает подвижность сперматозоидов). Цинк также повышает уровень тестостерона мужского полового гормона, играющего важную роль в нормальном течении сперматогенеза, положительно влияет на процессы деления и формирования клеток-предшественников сперматозоидов и обеспечивает правильное созревание сперматозоидов. Фолиевая кислота (фолацин) защищает хромосомы, находящиеся в сперматозоидах, от повреждения свободными радикалами. При недостатке этого компонента нарушаются процессы передачи генетической информации. Витамин Е (токоферол) также является антиоксидантом и защищает половые клетки от повреждающего воздействия свободных радикалов. Кроме того, витамин Е улучшает подвижность сперматозоидов и улучшает их оплодотворяющую способность. Глутатион и селен защищают мембраны сперматозоидов от разрушения, уменьшают вероятность повреждения ДНК сперматозоидов, повышая тем самым жизнеспособность эмбрионов. Достаточное количество этих компонентов в организме улучшает подвижность сперматозоидов. Витамин С (аскорбиновая кислота) - один из самых известных антиоксидантов. Он защищает генетический материал сперматозоидов от повреждающего действия свободных радикалов, а также укрепляет иммунитет. Экстракт женьшеня - природный адаптоген, который повышает устойчивость организма к эмоциональным и физическим перегрузкам. Кроме того, он повышает уровень тестостерона и увеличивает долю здоровых сперматозоидов в семенной жидкости. Докозагексаеновая кис- лота улучшает состав мембран сперматозоидов, увеличивает число сперматозоидов нормального строения, повышает подвижность, жизнеспособность сперматозоидов.

Пациенты принимали комплекс БЕСТФертил ${ }^{\circledR}$ в следующем режиме: по две капсулы «Утро» раз в день в первой половине дня и по две капсулы «Вечер» раз в день во второй половине дня во время приема пищи в течение шести месяцев. Через шесть месяцев проводилась оценка уровня гормонов, основных и дополнительных параметров эякулята (табл. 6-8).

По данным гормонограммы, значимых изменений на фоне при-
У пациентов старших возрастных групп применение комплекса БЕСТертил ${ }^{\circledR}$ способно повысить уровень антиоксидантной защиты и значительно улучшить показатели эякулята, в том числе увеличить количество прогрессивно подвижных и морфологически нормальных сперматозоидов, повысить их концентрацию, а также снизить уровень фрагментации ДНК сперматозоидов 
Таблица 8. Дополнительные параметры эякулята у пациентов стариих возрастных групп через шесть месяиев после лечения

\begin{tabular}{|c|c|c|c|c|c|c|c|c|c|c|}
\hline \multirow[t]{2}{*}{$\begin{array}{l}\text { Возраст } \\
\text { пациентов }\end{array}$} & \multicolumn{2}{|c|}{$\begin{array}{l}\text { Малоновый } \\
\text { диальдегид, } \\
\text { мкмоль/л }\end{array}$} & \multicolumn{2}{|l|}{ ГП, ед/л } & \multicolumn{2}{|l|}{ СОД, ед/л } & \multicolumn{2}{|c|}{\begin{tabular}{|l} 
Уровень \\
фрагментации ДНК \\
сперматозоидов, \% \\
\end{tabular}} & \multicolumn{2}{|c|}{ НВА-тест, \% } \\
\hline & \begin{tabular}{|l|} 
до \\
лечения
\end{tabular} & \begin{tabular}{|l} 
после \\
лечения
\end{tabular} & $\begin{array}{l}\text { до } \\
\text { лечения }\end{array}$ & \begin{tabular}{|l|} 
после \\
лечения
\end{tabular} & до лечения & \begin{tabular}{|l|} 
после \\
лечения
\end{tabular} & \begin{tabular}{|l} 
до \\
лечения
\end{tabular} & \begin{tabular}{|l|} 
после \\
лечения
\end{tabular} & \begin{tabular}{|l|} 
до \\
лечения
\end{tabular} & $\begin{array}{l}\text { после } \\
\text { лечения }\end{array}$ \\
\hline $41-45$ & $3,2 \pm 0,4$ & $2,7 \pm 0,5^{\star}$ & $399,1 \pm 19$ & $480 \pm 16,2^{*}$ & $192,5 \pm 25,1$ & $221 \pm 23,3^{*}$ & $15 \pm 0,8$ & $13 \pm 0,7$ & $72 \pm 3,4$ & $76 \pm 3,6$ \\
\hline $46-50$ & $3,6 \pm 0,4$ & $2,9 \pm 0,6^{*}$ & $320,5 \pm 17$ & $410 \pm 15,2^{\star}$ & $152,0 \pm 26,7$ & $194 \pm 18,4^{*}$ & $18 \pm 0,9$ & $15 \pm 0,6^{*}$ & $65 \pm 2,3$ & $72 \pm 1,8$ \\
\hline $51-55$ & $4,1 \pm 0,3$ & $3,4 \pm 0,3^{*}$ & $280,6 \pm 28$ & $390,3 \pm 16,2^{*}$ & $134,0 \pm 18,0$ & $162 \pm 16,3^{*}$ & $24 \pm 0,8$ & $16 \pm 1,2^{*}$ & $57 \pm 2,7$ & $64 \pm 2,3$ \\
\hline
\end{tabular}

Примечание. ГП - глутатионпероксидаза; СОД - супероксиддисмутаза.

* Разница по сравнению с показателями до лечения статистически значима $(\mathrm{p}<0,05)$.

менения препарата ни в одной возрастной группе не произошло (табл. 6).

\section{Обсуждение результатов}

С возрастом происходит ослабление системы антиоксидантной защиты сперматозоидов, которое выражается в снижении активности ферментов перекисного окисления липидов и приводит к различным нарушениям показателей эякулята, в частности уменьшению концентрации, подвижности, нарушению морфологии сперматозоидов и увеличению уровня фрагментации ДНК сперматозоидов.

На фоне приема комплекса БЕСТФертил ${ }^{\circledast}$ отмечалось улучшение показателей сперматогенеза наряду с изменением показателей ферментов антиоксидантной защиты, что можно интерпретировать как влияние на систему перекисного окисления липидов и повышение уровня антиоксидантной защиты эякулята. Чем выраженнее были нарушения показателей эякулята, тем значительнее оказались положительные изменения.

\section{Выводы}

У пациентов 40 лет и старше необходимо учитывать возрастные изменения организма: нарушение гормонального профиля, наличие сопутствующих заболеваний, выраженность окислительного стресса, что отрицательно влияет на показатели эякулята, в том числе повышает уровень фрагментации ДНК сперматозоидов и может негативно сказываться на качестве эмбрионов.

Через шесть месяцев после применения комплекса БЕСТФертил ${ }^{\circledR}$ у пациентов 40 лет и старше отмечено статистически значимое $(\mathrm{p}<0,05)$ улучшение основных параметров эякулята: рост концентрации сперматозоидов, увеличение количества прогрессивно подвижных и морфологически нормальных сперматозоидов.

С возрастом повышается уровень малонового диальдегида в эякуляте и одновременно ослабляется активность антиоксидантных ферментов, что свидетельствует о снижении антиоксидантной защиты эякулята. Через шесть месяцев после приема биоло- гически активного комплекса БЕСТФертил ${ }^{\circledast}$ показатели малонового диальдегида уменьшились на $18 \%$ от исходного уровня. Достоверное увеличение уровня глутатионпероксидазы (во всех возрастных группах в среднем на 25\%, в возрастной группе 51-55 лет до 39\%) и супероксиддисмутазы на фоне использования препарата комплексного действия БЕСТФертил ${ }^{\circledast}$ позволило говорить о повышении уровня защиты сперматозоидов от окислительного стресса.

После курса приема комплекса БЕСТФертил ${ }^{\circledast}$ статистически значимо ( $<0,05)$ снизился уровень фрагментации ДНК сперматозоидов. Через шесть месяцев доля сперматозоидов с фрагментированной ДНК достоверно уменьшилась на $32 \%$ от исходного уровня.

Применение многокомпонентного препарата БЕСТФертил ${ }^{\circledR}$ способно повысить уровень антиоксидантной защиты и значительно улучшить показатели эякулята, в том числе у пациентов старших возрастных групп.

\section{Литература}

1. Божедомов В.А., Теодорович О.В. Эпидемиология и причины аутоиммунного мужского бесплодия // Урология. 2005. № 1. С. 35-44.

2. Laboratory manual for the examination of human semen and sperm-cervical mucous interaction / World Health Organization. $4^{\text {th }}$ ed. New York: Cambridge University Press, 1999.

3. Тер-Аванесов Г.В. Андрологические аспекты бесплодного брака // Практическое руководство. М., 2000.

4. Manual for the standardized investigation and diagnosis of the infertile couple / World Health Organiza- tion. $3^{\text {th }}$ ed. New York: Cambridge University Press, 2000.

5. Нишлаг Э., Бере Г.М. Андрология. Мужское здоровье и дисфункция репродуктивной системы: пер. с английского. М.: Медицинское информационное агентство, 2005.

6. Tremellen K., Miari G., Froiland D., Thompson J. A randomised control trial examining the effect of an antioxidant (Menevit) on pregnancy outcome during IVFICSI treatment // Aust. N. Z. J. Obstet. Gynaecol. 2007. Vol. 47. № 3. P. 216-221.

7. Гамидов С.И., Иремашвили В.В., Тхагопсоева П.А. Терапия нарушения фертильности у мужчин: перспективные результаты европейских исследований // 
Эффективная фармакотерапия. Урология и нефрология. 2009. № 2. С. 26-30.

8. Зоркин С.Н., Чеботаев И.Л., Смирнов И.Е., Баканов М.И. Оксид азота как показатель эндотелиальной дисфункции при варикоцеле // Материалы Международного конгресса по андрологии 28-29 мая 2009, Сочи, ОК «Дагомыс» УД Президента РФ. Сочи, 2009. C. $144-145$.

9. Agarwal A., Said T.M. Oxidative stress, DNA damage and apoptosis in male infertility: a clinical approach // BJU Int. 2008. Vol. 95. № 4. P. 503-507.

10. De Lamirande E., Gagnon C. The dark and bright sides of reactive oxygen species on sperm function // The male gamete: from basic science to clinical application / ed. by C. Gagnon. Cache River Press, Vienna, 1999. P. 455-467.

11. Aitken R.J., Gordon E., Harkiss D. et al. Relative impact of oxidative stress on the functional competence andgenomic integrity of human spermatozoa // Biol. Reprod. 1998. Vol. 59. № 5. P. 1037-1046.

12. Громенко Д.С. Применение наукоемких технологий для оценки фертильности мужчин // Вестник новых медицинских технологий. 2008. Т. 15. № 4. C. $118-120$.

13. Bonduelle M., Joris H., Hofmans K. et al. Mental development of 201 ICSI children at 2 years of age // Lancet. 1998. Vol. 351. № 9115. ID 1553.

14. Bowen J.R., Gibson F.L., Leslie G.I., Saunders D.M. Medical and developmental outcome at 1 year for children conceived by intracytoplasmic sperm injection // Lancet. 1998. Vol. 351. № 9115. P. 1529-1534.

15. Zorn B., Sesek-Briski A., Osredkar J., Meden-Vrtovec H. Semen polymorphonuclear neutrophil leukocyte elastase as a diagnostic and prognostic marker of genital tract inflammation a review // Clin. Chem. Lab. Med. 2003. Vol. 41. № 1. P. 2-12.

16. Aitken R.J., Harkiss D., Knox W. et al. A novel signal transduction cascade in capacitating human spermatozoa characterised by a redox-regulated, cAMP-mediat- ed induction of tyrosine phosphorylation // J. Cell Sci. 1998. Vol. 111. Pt. 5. P. 645-656.

17. Kao S.H., Chao H.T., Chen H.W. et al. Increase of oxidative stress in human sperm with lower motility // Fertil. Steril. 2007. Vol. 89. № 5. P. 1183-1190.

18. Kemal Duru N., Morshedi M., Oehninger S. Effects of hydrogen peroxide on DNA and plasma membrane integrity of human spermatozoa // Fertil. Steril. 2000. Vol. 74. № 6. P. 1200-1207.

19. Loft S., Kold-Jensen T., Hjollund N.H. et al. Oxidative DNA damage in human sperm influences time to pregnancy // Hum. Reprod. 2003. Vol. 18. № 6. P. 1265-1272.

20. Meseguer M., de los Santos M.J., Simon C. et al. Effect of sperm glutathione peroxidases 1 and 4 on embryo asymmetry and blastocyst quality in oocyte donation cycles // Fertil. Steril. 2006. Vol. 86. № 5. P. 1376-1385.

21. Tremellen K., Miari G., Froiland D., Thompson J. A randomised control trial examining the effect of an antioxidant (Menevit) on pregnancy outcome during IVF-ICSI treatment // Aust. N. Z. J. Obstet. Gynaecol. 2007. Vol. 47. № 3. P. 216-221.

22. Hochreiter W.W., Ackermann D.K., Brütsch H.P. Andropause // Ther. Umsch. 2005. Vol. 62. № 12. P. 821-826.

23. Sheweita S.A., Tilmisany A.M., Al-Sawaf H. Mechanisms of male infertility: role of antioxidants // Curr. Drug Metab. 2005. Vol. 6. № 5. P. 495-501.

24. Nunomura A., Moreira P.I., Castellani R.J. et al. Oxidative damage to RNA in aging and neurodegenerative disorders // Neurotox. Res. 2012. Vol. 22. № 3. P. 231-248.

25. Sikka S.C. Relative impact of oxidative stress on male reproductive function // Curr. Med. Chem. 2001. Vol. 8. № 7. P. 851-862.

26. Agarwal A., Allamaneni S.S. Free radicals and male reproduction // J. Indian Med. Assoc. 2011. Vol. 109. № 3. P. $184-187$.

27. Реброва О.Ю. Статистический анализ медицинских данных. Применение пакета прикладных программ STATISTICA. М.: МедиаСфера, 2000.

\title{
Features of Ejaculate Indicators and Methods of Spermatogenesis Disorders Correction
} in Men of Different Age Groups

\author{
R.T. Aliev, MD, PhD, Prof. ${ }^{1,2}$, R.R. Aliev³, S.M. Pikalov ${ }^{4}$ \\ ${ }^{1}$ State Research Center - Burnasyan Federal Medical Biophysical Center, Moscow \\ ${ }^{2}$ Regional Clinical Hospital, Barnaul \\ ${ }^{3}$ Altay Medical State University, Barnaul \\ ${ }^{4}$ Samara Regional Clinical Hospital named after V.D. Seredavin
}

Contact person: Roman T. Aliev, romanaliev@yandex.ru

The results of studying the fertility disorders problem in men are provided. At the first stage it was found that in men of the older age group (over 40 years) the volume of ejaculate is less, the level of progressively mobile and morphologically normal sperm is lower. In addition, they have the weakened antioxidant protection of the ejaculate, reduced testicular function and increased level of sperm DNA fragmentation. At the second stage, patients of 40 years and older took $B E S T F e r t i l^{\circ}$ complex, which contributed to a statistically significant $(p<0.05)$ improvement of the ejaculate main parameters, increase the level of antioxidant protection and reduce the level of sperm DNA fragmentation.

Key words: spermatogenesis, ejaculate, male infertility 